\title{
Persistence and photochemical decay of springtime total ozone anomalies in the Canadian Middle Atmosphere Model
}

\author{
S. Tegtmeier ${ }^{1, *}$ and T. G. Shepherd ${ }^{2}$ \\ ${ }^{1}$ Alfred Wegener Institute for Polar and Marine Research, Potsdam, Germany \\ ${ }^{2}$ Department of Physics, University of Toronto, Toronto, Ontario, Canada \\ * now at: Department of Physics, University of Toronto, Canada
}

Received: 19 January 2006 - Published in Atmos. Chem. Phys. Discuss.: 28 April 2006

Revised: 19 December 2006 - Accepted: 21 December 2006 - Published: 25 January 2007

\begin{abstract}
The persistence and decay of springtime total ozone anomalies over the entire extratropics (midlatitudes plus polar regions) is analysed using results from the Canadian Middle Atmosphere Model (CMAM), a comprehensive chemistry-climate model. As in the observations, interannual anomalies established through winter and spring persist with very high correlation coefficients (above 0.8 ) through summer until early autumn, while decaying in amplitude as a result of photochemical relaxation in the quiescent summertime stratosphere. The persistence and decay of the ozone anomalies in CMAM agrees extremely well with observations, even in the southern hemisphere when the model is run without heterogeneous chemistry (in which case there is no ozone hole and the seasonal cycle of ozone is quite different from observations). However in a version of CMAM with strong vertical diffusion, the northern hemisphere anomalies decay far too rapidly compared to observations. This shows that ozone anomaly persistence and decay does not depend on how the springtime anomalies are created or on their magnitude, but reflects the transport and photochemical decay in the model. The seasonality of the long-term trends over the entire extratropics is found to be explained by the persistence of the interannual anomalies, as in the observations, demonstrating that summertime ozone trends reflect winter/spring trends rather than any change in summertime ozone chemistry. However this mechanism fails in the northern hemisphere midlatitudes because of the relatively large impact, compared to observations, of the CMAM polar anomalies. As in the southern hemisphere, the influence of polar ozone loss in CMAM increases the midlatitude summertime loss, leading to a relatively weak seasonal dependence of ozone loss in the Northern Hemisphere compared to the observations.
\end{abstract}

Correspondence to: $\mathrm{S}$. Tegtmeier

(susann@atmosp.physics.utoronto.ca)

\section{Introduction}

Fioletov and Shepherd (2003, hereinafter referred to as F\&S 2003) showed that interannual total ozone anomalies in midlatitudes develop through the winter and spring, and then persist through summer until autumn. Weber et al. (2003) showed that these anomalies (in both spring and late summer) are related to anomalies in the dynamical forcing of the Brewer-Dobson circulation. During winter and early spring there is a buildup of ozone which is caused by the dominance of transport processes during this period. This buildup is followed by a decline through late spring and summer when transport becomes less important and photochemical loss controls the time evolution of midlatitude total ozone. During this summertime period of total ozone decline the ozone anomalies decrease in magnitude through photochemical relaxation, and then are rapidly erased when the next winter's buildup begins. In general the persistence of the midlatitude ozone anomalies is stronger in the northern hemisphere $(\mathrm{NH})$ than in the southern hemisphere $(\mathrm{SH})$. This is due to the influence of springtime polar ozone depletion on midlatitude ozone after the breakup of the vortex. Fioletov \& Shepherd (2005, hereinafter referred to as F\&S 2005) went on to show that the persistence of the total ozone anomalies is much greater in the $\mathrm{SH}$ when the entire extratropics $\left(35^{\circ} \mathrm{S}-\right.$ $80^{\circ} \mathrm{S}$ ) is included, since the region is then not sensitive to transport across $60^{\circ} \mathrm{S}$. (The region poleward of $80^{\circ}$ latitude is not observed by TOMS or SBUV, but because of the very small area involved contributes very little to the entire extratropical amounts.)

These observed relationships provide a valuable diagnostic for process-oriented model validation. The F\&S 2003 approach is used here to compare the persistence and photochemical decay of total ozone anomalies in the Canadian Middle Atmosphere Model (CMAM) with observations.

Published by Copernicus GmbH on behalf of the European Geosciences Union. 
TOMS \& SBUV
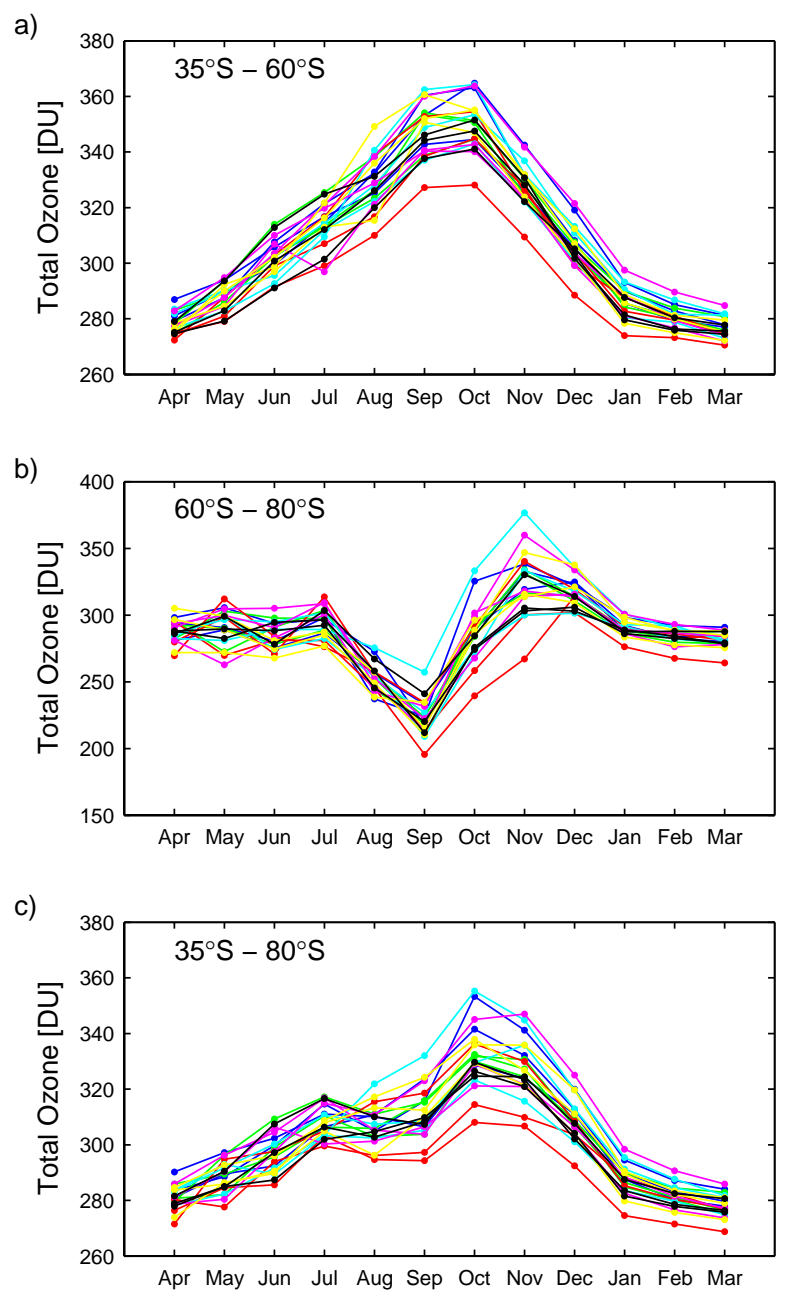

CMAM
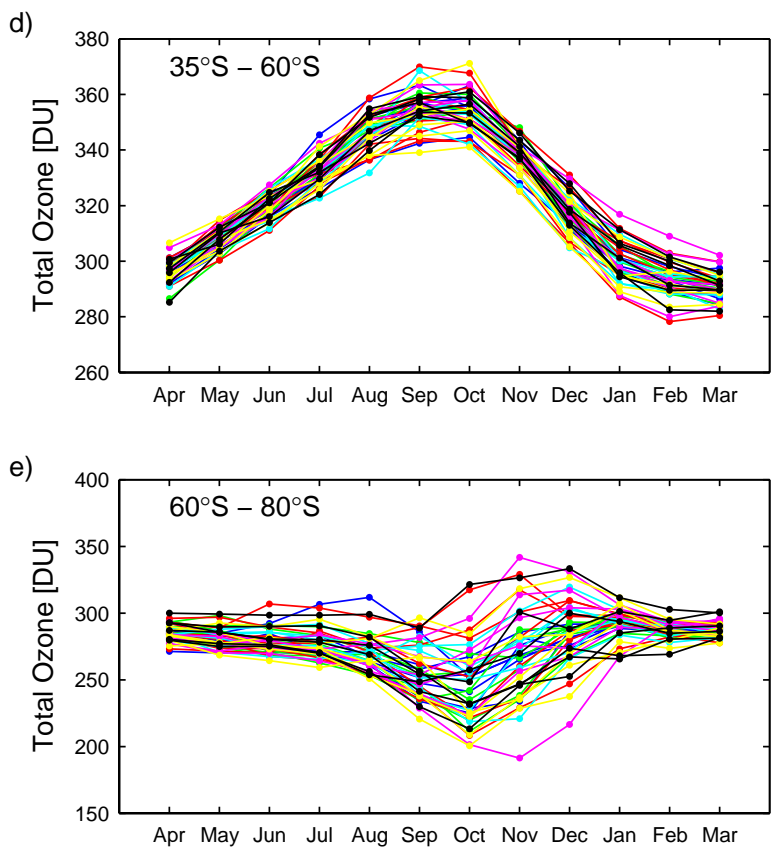

f)

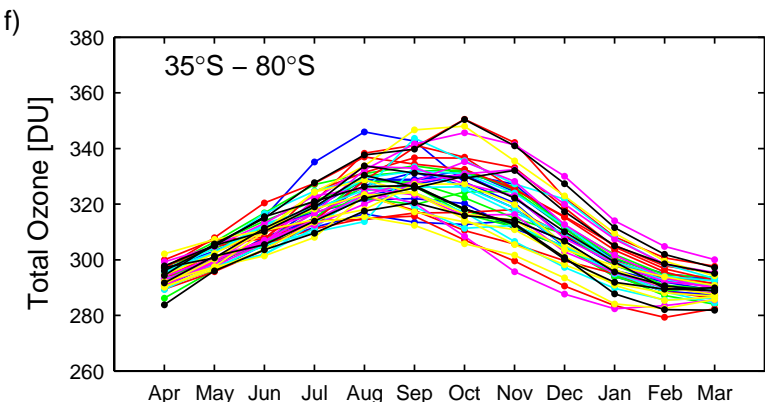

Fig. 1. Seasonal cycle of area weighted total ozone values averaged over SH midlatitudes $\left(35^{\circ} \mathrm{S}-60^{\circ} \mathrm{S}\right)$, polar latitudes $\left(60^{\circ} \mathrm{S}-80^{\circ} \mathrm{S}\right)$, and the entire extratropical region $\left(35^{\circ} \mathrm{S}-80^{\circ} \mathrm{S}\right)$, for the merged TOMS \& SBUV data set on the left hand side and for CMAM on the right hand side. Each curve corresponds to a different year. The values are the anomalies from the long term trend added to the EESC fit for the year 2000.

\section{Data sets and methodology}

We use the same version of the merged satellite data set as in F\&S 2005. The set is prepared by NASA and combines version 8 of the TOMS and SBUV data for the time period from November 1978 to December 2003 (Frith et al., 2004). The zonal mean total ozone values cover up to $80^{\circ} \mathrm{N}$ from April to September in the $\mathrm{NH}$ and up to $80^{\circ} \mathrm{S}$ from October to March in the SH. The data for August and September 1995 as well as May and June 1996 are missing. We use estimates of total ozone from ground based measurements to fill the gaps (Fioletov et al., 2002). The 24-year time series of each month consists of monthly and zonal means which are area weighted and averaged over certain latitude bands.

The CMAM is a three-dimensional chemistry-climate model with comprehensive physical parameterisations (Beagley et al., 1997; de Grandpré et al., 2000). The version used here has a domain from the surface of the earth to approximately $97 \mathrm{~km}$ and T32 spectral truncation. The model includes a fully interactive stratospheric chemistry with all the relevant catalytic ozone loss cycles and heterogeneous reactions for sulphate aerosols, liquid ternary solutions (the socalled Type 1b Polar Stratospheric Clouds, PSCs) and water ice (Type 2 PSCs). There is no parameterisation of nitric acid trihydrate PSCs (Type 1a PSCs) or any associated denitrification. To calculate the persistence and photochemical decay of total ozone anomalies in CMAM we use ozone data from a 45-year transient run of the model. The run (Eyring et al., 2006) was performed for the period 1960-2004 and was forced by observed changes in well-mixed greenhouse gases, 
halogens, and sea-surface temperatures.

The total ozone autocorrelations were calculated for the entire extratropics for both hemispheres $\left(35^{\circ}-80^{\circ}\right.$ latitude) as a function of time lag for each month of the year. The autocorrelation is thus

$$
R(t, \tau)=\frac{\sum_{i=1}^{n} f_{i}(t) f_{i}(t+\tau)}{\sqrt{\sum_{i=1}^{n} f_{i}(t)^{2}} \sqrt{\sum_{i=1}^{n} f_{i}(t+\tau)^{2}}}
$$

where $n$ is the number of years in the record, $t$ is a particular month, $t+\tau$ is a subsequent month lagged by $\tau$ months, and $f_{i}$ is the deviation from the mean in the year $i$. The correlation coefficients between ozone values for the same month in different years are low. Thus each year can be considered as independent and correlation coefficients greater than 0.4 are statistically significant at the $95 \%$ confidence level for the observations, and greater than 0.3 for CMAM.

As in F\&S 2005 we scale the equivalent effective stratospheric chlorine (EESC) (WMO, 2003) trend to be one unit per year during the 1980s and use the scaled EESC loading as a proxy for the long term trend of each time series. Thus we can express the trend coefficients in DU/year during the 1980s. We remove the EESC fit prior to the anomaly analysis.

\section{Short-term variations}

Figure 1 shows the seasonal cycle of total ozone in the $\mathrm{SH}$ from both observations and from CMAM, averaged over $35^{\circ} \mathrm{S}-60^{\circ} \mathrm{S}, 60^{\circ} \mathrm{S}-80^{\circ} \mathrm{S}$ and $35^{\circ} \mathrm{S}-80^{\circ} \mathrm{S}$ for each year in the relevant data sets. The values are the anomalies from the long term trend added to the EESC fit for the year 2000. In this way, the absolute values of the two data sets are directly comparable even though the data sets cover different time periods. The seasonal cycle of total ozone shows a late spring maximum in midlatitudes and a late spring minimum in polar regions, the latter reflecting the springtime polar ozone depletion. In autumn CMAM midlatitude ozone levels exhibit a positive bias of about $10 \mathrm{DU}$ relative to observations. Furthermore, the seasonal cycle of total ozone for the entire extratropical region is slightly stronger in the observations.

As noted in F\&S 2003, the anomalies established in spring appear to persist through the summer. This is illustrated by Fig. 2, which shows the year to year variability of total ozone anomalies averaged over the $\mathrm{SH}$ extratropics for the four spring/early summer months for both observations and model. The interannual anomalies are highly correlated from month to month, and the anomalies established in October decrease continuously through January. Since the seasonal cycle of the CMAM ozone is somewhat too weak the overall absolute decrease in ozone values during the four months is smaller in CMAM than in the observations, but the magnitude of the year to year variability of each month is in reasonably good agreement between the two data sets.
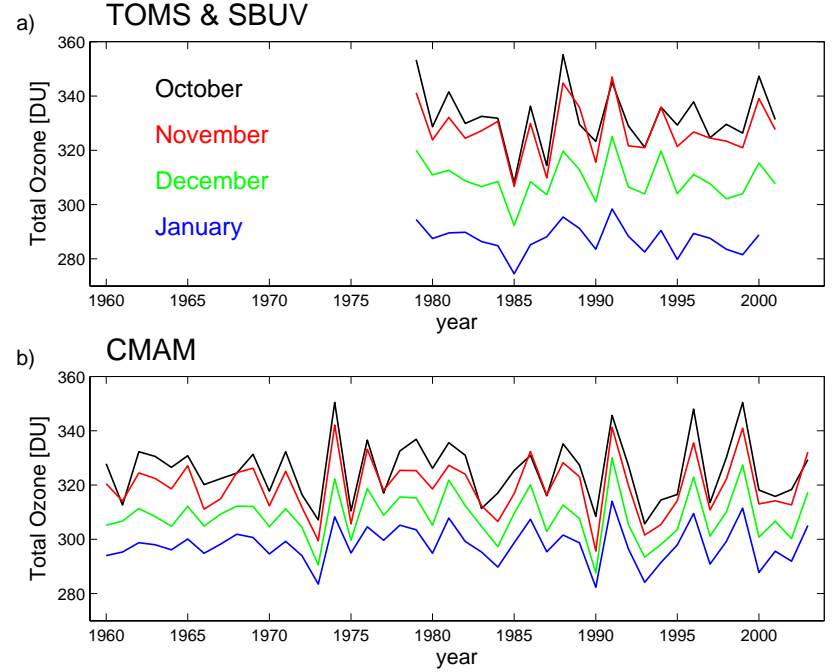

Fig. 2. Time series of total ozone anomalies (normalized to the year 2000) averaged over $35^{\circ} \mathrm{S}-80^{\circ} \mathrm{S}$ for the four spring/early summer months for the observations and for CMAM.

Figure 3 shows the correlation coefficients between ozone values at a given month of the year with ozone values at subsequent months for the SH extratropics. Colours other than grey denote statistically significant correlations at the $95 \%$ confidence level assuming each year is independent. The correlations are extremely high (above 0.8 ) in summer (November until February) with any later month up to March, and statistically significant up to April in the observations and June in CMAM. Thus, it is evident that the anomalies persist from the end of spring until early autumn in both observations and the CMAM. This high predictability of total ozone reflects the fact that there is not a great deal of dynamical variability in the summer stratosphere, and so the time evolution of ozone (integrated over the extratropics) is controlled by photochemical relaxation.

The relationship between ozone anomalies in November and in subsequent months can be estimated by linear regression, and is shown in Fig. 4. The regression coefficients illustrate that the amplitude of the ozone anomalies decays on a timescale of a few months through photochemical ozone loss. Again the CMAM results are very similar to the observations, indicating that the overall summertime ozone photochemistry in the model is reasonable.

Since the diagnostic reflects transport and summertime photochemistry, it should not depend on how the springtime ozone anomaly is created. To verify this hypothesis we examine results from a different version of CMAM which includes no heterogeneous chemistry and thus has no ozone hole. Two 15-year simulations were used here to obtain a combined 30-year ozone data set. The two model runs were performed under fixed external forcings corresponding to conditions in 2000 with annually repeating climatological 

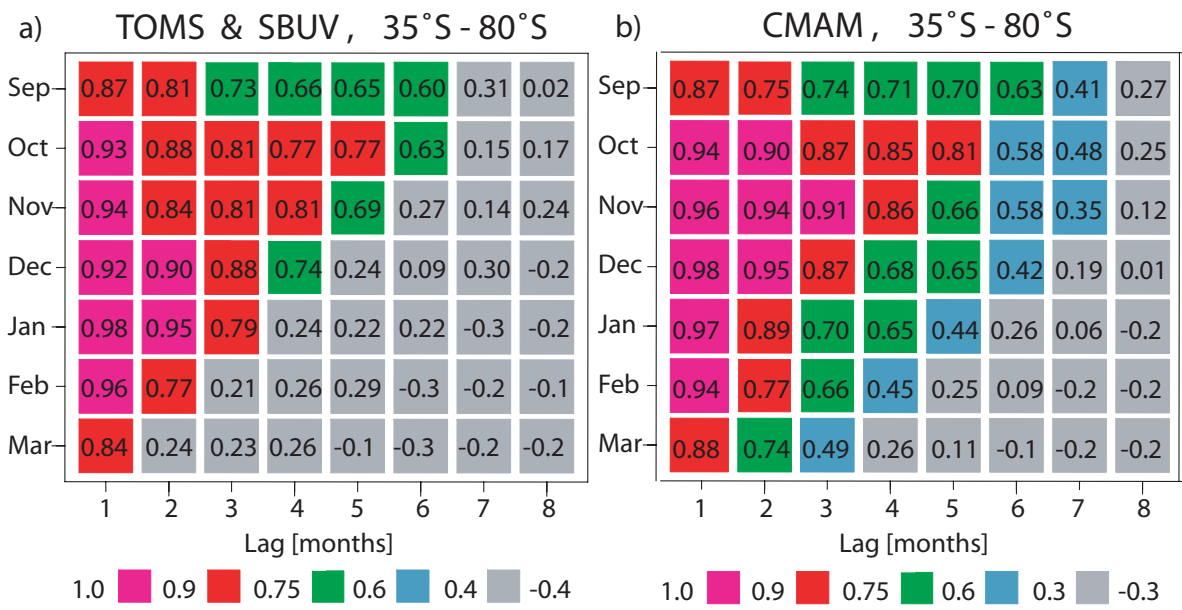

Fig. 3. Correlation coefficients between ozone anomalies at a given month of the year with ozone anomalies at subsequent months for $35^{\circ} \mathrm{S}-80^{\circ} \mathrm{S}$, for the observations and for CMAM. Values shaded gray are not statistically significant at the $95 \%$ level.

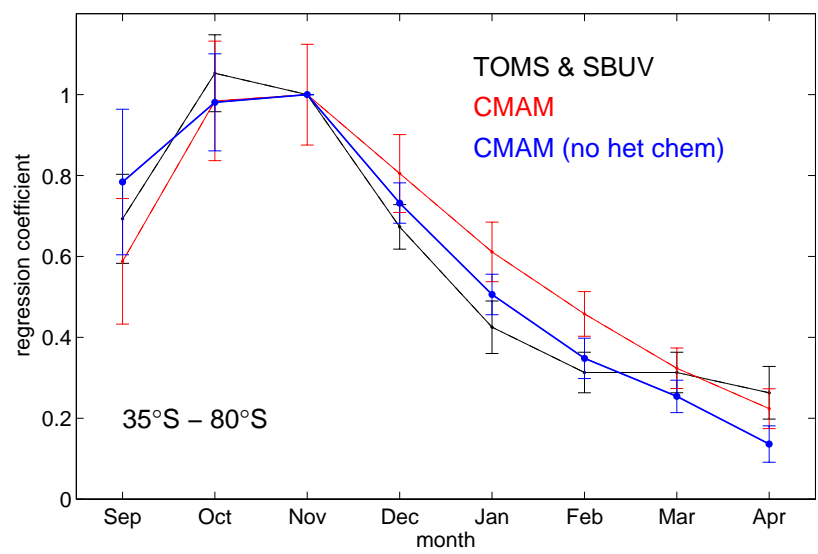

Fig. 4. Linear regression coefficients between $35^{\circ} \mathrm{S}-80^{\circ} \mathrm{S}$ ozone anomalies in November and in other months of the year for the observations (black), the transient CMAM run with heterogeneous chemistry (red), and a CMAM time slice run without heterogeneous chemistry (blue). The error bars indicate the $1 \sigma$ uncertainty.

sea surface temperatures. Since there is no springtime polar ozone depletion, the seasonal cycle of ozone has a late spring maximum in polar regions and hence a strong seasonal cycle (in fact approaching that of the $\mathrm{NH}$ ) in the entire $\mathrm{SH}$ extratropical region. However, the persistence of springtime ozone anomalies and the photochemical decay is very similar to that in the observations as well as in the other CMAM run, as shown in Fig. 4. This confirms that the diagnostic only reflects the transport and summertime photochemistry, and not the nature of the springtime ozone anomaly.

We now return to the 45 -year transient run and examine the behaviour in the NH. Figure 5 shows the seasonal cycle of total ozone over $35^{\circ} \mathrm{N}-60^{\circ} \mathrm{N}, 60^{\circ} \mathrm{N}-80^{\circ} \mathrm{N}$, and $35^{\circ} \mathrm{N}-$ $80^{\circ} \mathrm{N}$ for the observations and CMAM and as before, the values are the anomalies from the long term trend added to the EESC fit for the year 2000. The seasonal cycles are in good agreement, but CMAM has comparatively limited interannual variability in midlatitudes and thus over $35^{\circ} \mathrm{N}-80^{\circ} \mathrm{N}$ as a whole. This deficiency is evident in other diagnostics using an earlier version of CMAM (Austin et al., 2003).

Figure 6 shows the correlation coefficients between ozone anomalies in different months for the $\mathrm{NH}$ extratropics. In the observations (Fig. 6a) the anomalies persist from the end of spring during the whole summer until early autumn. The CMAM anomalies (Fig. 6b), although small in magnitude, show the same characteristics. The CMAM correlation coefficients are very similar to the observations, except for March where the correlations are somewhat smaller in CMAM. The decay of the anomalies is shown in Fig. 7 and is virtually identical between CMAM and the observations.

Since the diagnostic reflects transport and summertime photochemistry, it should depend on transport characteristics like the vertical diffusion coefficient. To verify this hypothesis we examine results from an older version of CMAM which has a much stronger and therefore less realistic (WMO, 1999) vertical diffusion coefficient $\left(1.0 \mathrm{~m}^{2} / \mathrm{s}\right)$ compared to the 45 -year transient CMAM run $\left(0.1 \mathrm{~m}^{2} / \mathrm{s}\right)$. The strong diffusion run was performed under fixed external forcings corresponding to conditions in 2000 with annually repeating climatological sea surface temperatures. Figure $6 \mathrm{c}$ shows the correlation coefficients between monthly ozone anomalies for the strong diffusion run. These coefficients are smaller than for the observations or the transient CMAM run, especially in spring and early summer. It is most likely that the rapid decay of the anomalies is due to the stronger vertical diffusion. Consistently, the regression coefficients for the strong diffusion run are smaller than in the observations or the transient CMAM run as illustrated by Fig. 7. This confirms that the diagnostic is sensitive to summertime vertical 

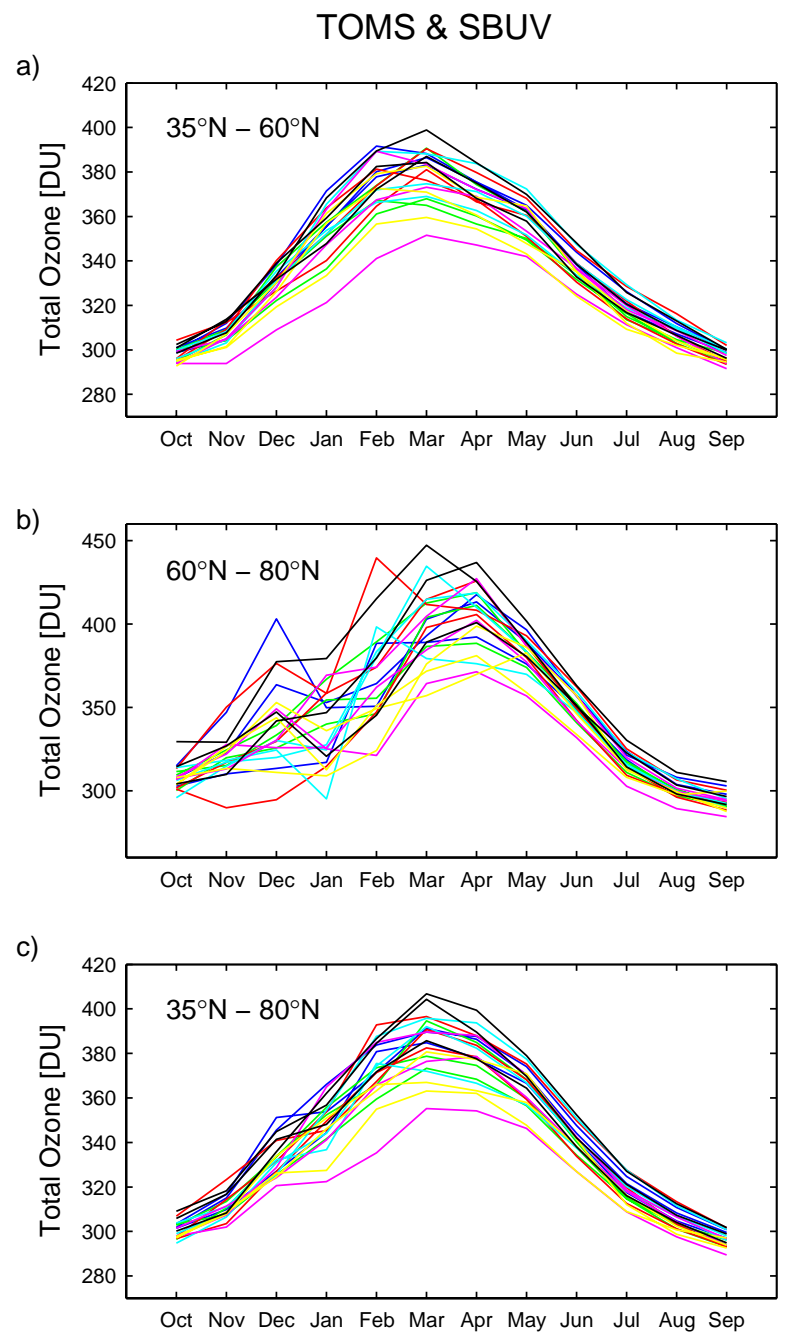

Fig. 5. As in Fig. 1, but for the NH.

transport, and can detect an unrealistically strong vertical diffusion coefficient.

\section{Long-term variations}

The long-term change in total ozone from observations and from the 45-year transient CMAM run associated with the EESC loading is shown in Fig. 8. The trend coefficients can be expressed in terms of the linear trend during the 1980s (see Sect. 2) and are estimated separately for each month of the year. The magnitude of the trends are weaker in CMAM than in the observations, especially in the northern hemisphere. This is not unusual for CCMs (Eyring et al., 2006). Overall the trend functions of ozone show similar characteristics in the observations and CMAM. The seasonal cycle of the ozone trends have a maximum in spring which is especially strong in the polar regions, reflecting the polar springtime ozone depletion. The polar springtime ozone
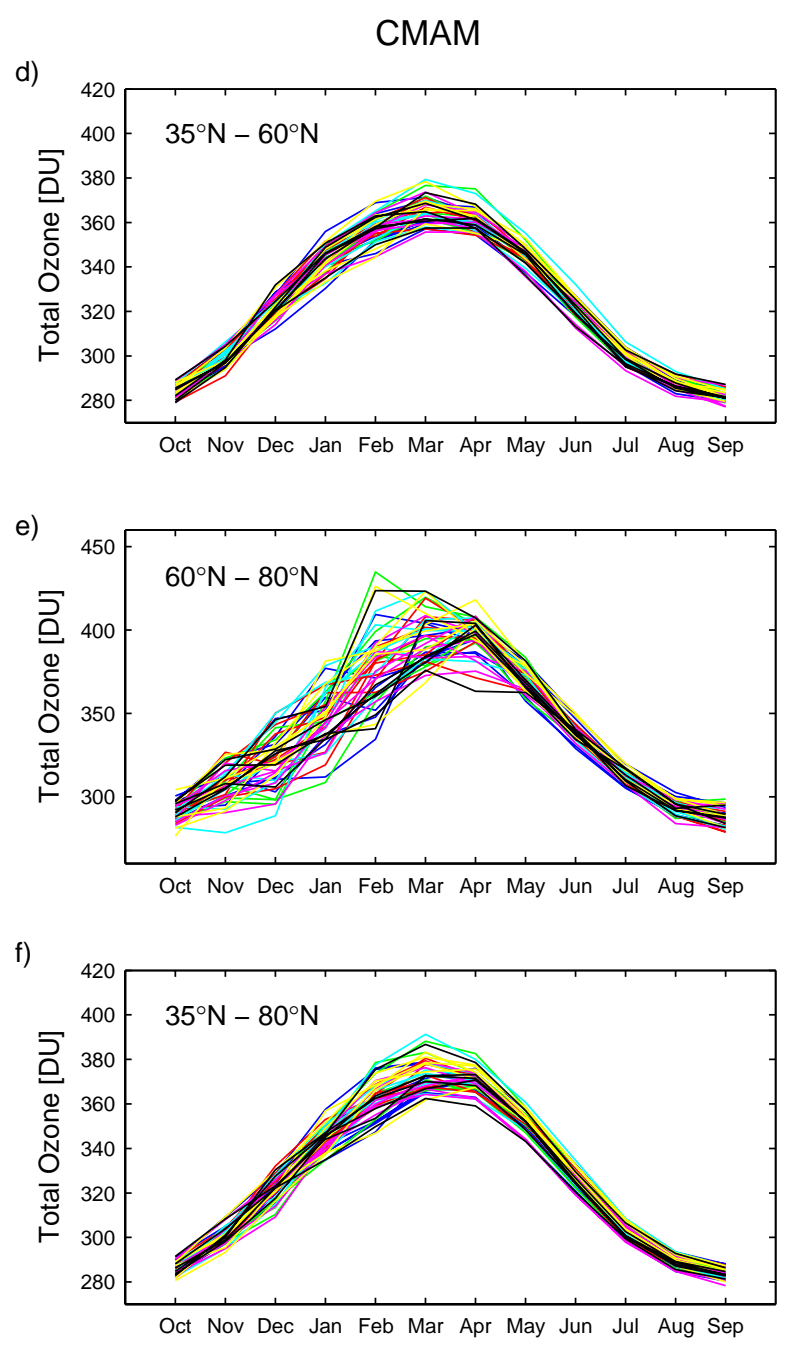

trends are clearly stronger in the SH. In both hemispheres the polar trends amplify the seasonal cycle of the ozone trends for the entire extratropical region compared to the midlatitudes. However the summertime trends are nearly identical over middle and polar latitudes.

F\&S 2003 demonstrated that in the NH midlatitudes the observed long-term trends are determined by the trends in the winter/spring buildup. There is no need to invoke summertime ozone chemistry or springtime polar ozone depletion to explain the summertime ozone trends in the NH. In contrast the seasonality of observed trends in the southern midlatitudes cannot be explained by the springtime trends there. As noted in F\&S 2005 the mechanism works better in the SH if the entire extratropical region $\left(35^{\circ} \mathrm{S}-80^{\circ} \mathrm{S}\right)$ is considered, implying that springtime polar ozone depletion and transport contribute to the summer ozone trend over SH midlatitudes.

We now examine if the trend function of total ozone from CMAM from summer through to early autumn can be 
a)

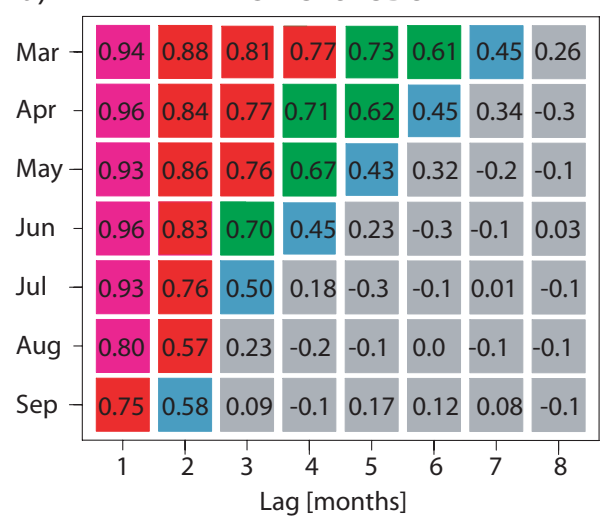

b)

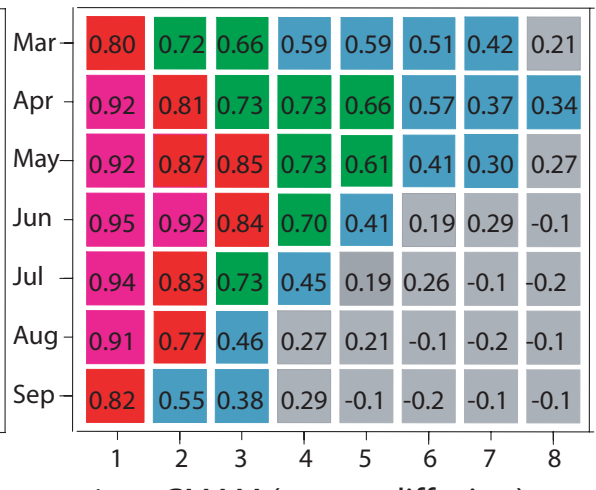

c) CMAM (strong diffusion)

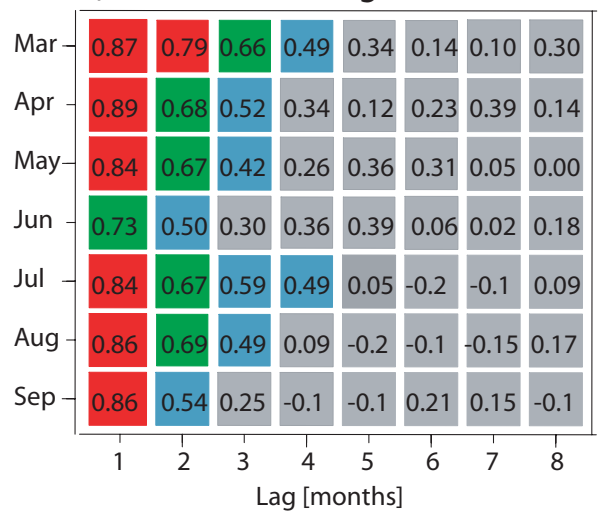

Fig. 6. Correlation coefficients between ozone anomalies at a given month of the year with ozone anomalies at subsequent months for $35^{\circ} \mathrm{N}-80^{\circ} \mathrm{N}$, for the observations, the transient CMAM run, and a CMAM time slice run with strong vertical diffusion. Values shaded gray are not statistically significant at the $95 \%$ level.

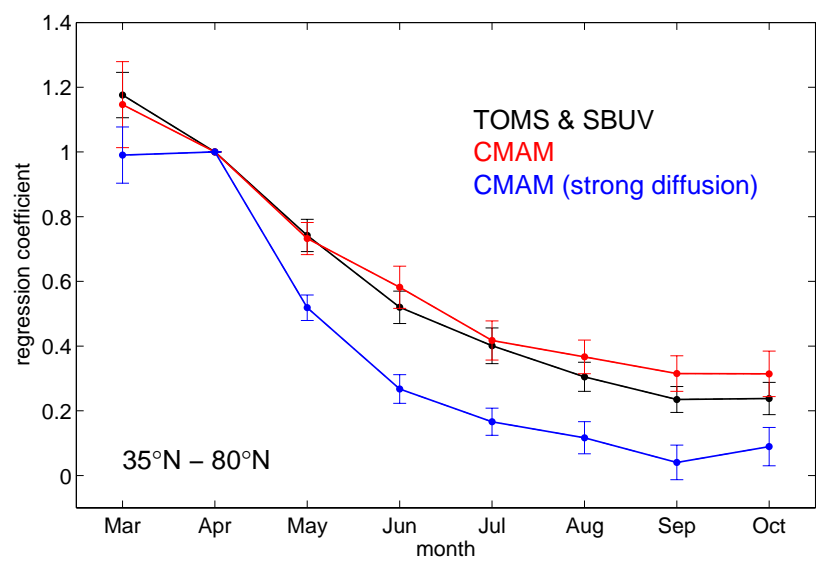

Fig. 7. Linear regression coefficients between $35^{\circ} \mathrm{N}-80^{\circ} \mathrm{N}$ ozone anomalies in April and in other months of the year for observations (black) the transient CMAM run (red), and a CMAM time slice run with strong vertical diffusion (blue). The error bars indicate the $1 \sigma$ uncertainty.

explained by the springtime trends. Therefore we estimate the trend for each month by multiplying the trend value for a specific selected springtime month with the regression coefficient between the two months. Figures $9 \mathrm{c}$ and $\mathrm{d}$ show the results for the $\mathrm{SH}$ midlatitude and extratropical regions based on the trend values for October, November or December. The actual trend function is also displayed. In the southern midlatitudes the actual trend in summer is significantly stronger than the estimated trends. If, however, the entire extratropical region is considered then the estimates of summertime trends from springtime trends work much better and show the same seasonality as the actual trend function. These results are consistent with the observations.

In the same way, the long-term trends are in line with interannual variability over the entire northern extratropics. This is illustrated by Fig. 9b, which shows the actual trend function from late spring through early autumn together with the estimates of the trend based on the actual trend values for March, April, or May and the regression coefficients for the interannual anomalies. However there are differences between CMAM and the observations for northern midlatitudes. In the observations, F\&S 2003 showed that interannual anomalies in NH midlatitudes persist through summer, despite the mixing in of polar air following the vortex breakdown. This is because in terms of total ozone mass, 

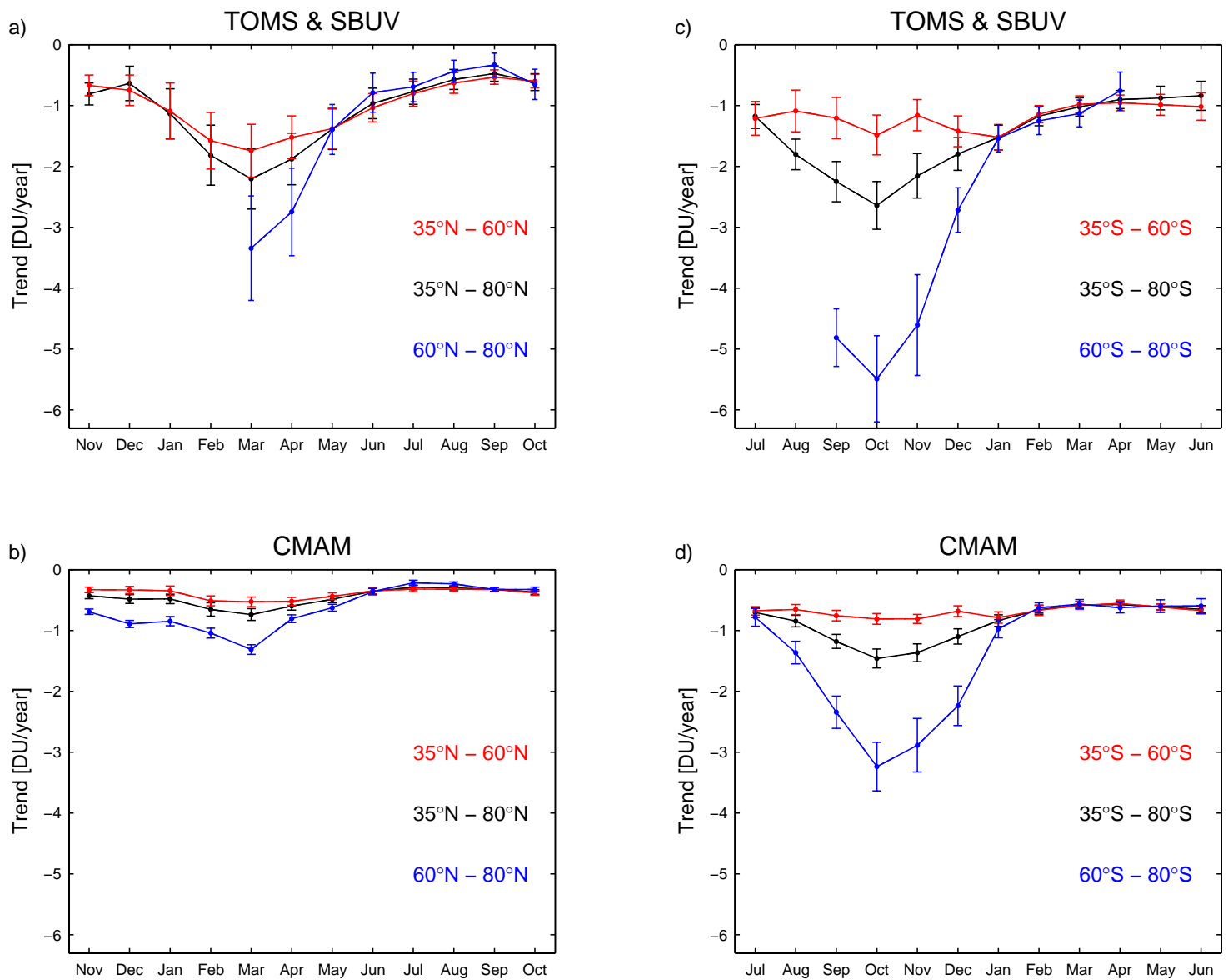

Fig. 8. Total ozone trends for midlatitudes $\left(35^{\circ}-60^{\circ}\right.$, red), polar latitudes $\left(60^{\circ}-80^{\circ}\right.$, blue), and the entire extratropical region $\left(35^{\circ}-80^{\circ}\right.$, black) for the northern (left) and southern (right) hemispheres. The observed total ozone trends are shown in the two top panels and the ozone trends for the 45-year transient CMAM run are shown in the two bottom panels. The trends are based on a fit to EESC and are expressed in terms of DU/year during the 1980s (see text for details). The error bars indicate the $1 \sigma$ uncertainty.

the midlatitude anomalies dominate over the polar anomalies; the anomalies seen in Fig. 5 are multiplied by the area of the region. However in CMAM the midlatitude anomalies decay rapidly after the vortex breakdown (not shown here), because of the much larger impact of the CMAM polar anomalies. As in the SH the estimated trends underpredict the summertime trends in NH midlatitudes in CMAM (Fig. 9a). This is in contrast to the observations. The implication is that in CMAM the relative importance of Arctic ozone loss is greater than in the observations, just as the interannual Arctic anomalies in CMAM have an unrealistically large relative impact on the overall extratropical anomalies (Fig. 5).

\section{Summary}

The persistence and photochemical decay of springtime total ozone anomalies in CMAM integrated over $35^{\circ}-80^{\circ}$ latitude in both hemispheres is very realistic. The behaviour in the
SH is similar for simulations with and without heterogeneous chemistry, i.e. with or without an ozone hole. The behaviour in the NH is realistic despite unrealistically low ozone variability, but is unrealistic for a simulation with very strong vertical diffusion. This shows that the diagnostic from $F \& S$ 2003 does not depend on how the springtime anomalies are created or on their magnitude, but reflects the transport and photochemical decay in the model - as one would expect.

For the entire extratropical region the seasonality of the long-term ozone trends in CMAM for summer through early autumn can be explained by the persistence of the interannual springtime anomalies, as in the observations. This implies that summertime ozone trends are a result of the springtime trends, without the need to invoke changes in summertime chemistry. By considering the entire extratropical region, transport of ozone-depleted air from the polar into the midlatitude regions following the breakdown of the polar vortex does not affect the relation between springtime and summertime ozone anomalies and long-term trends. However this 

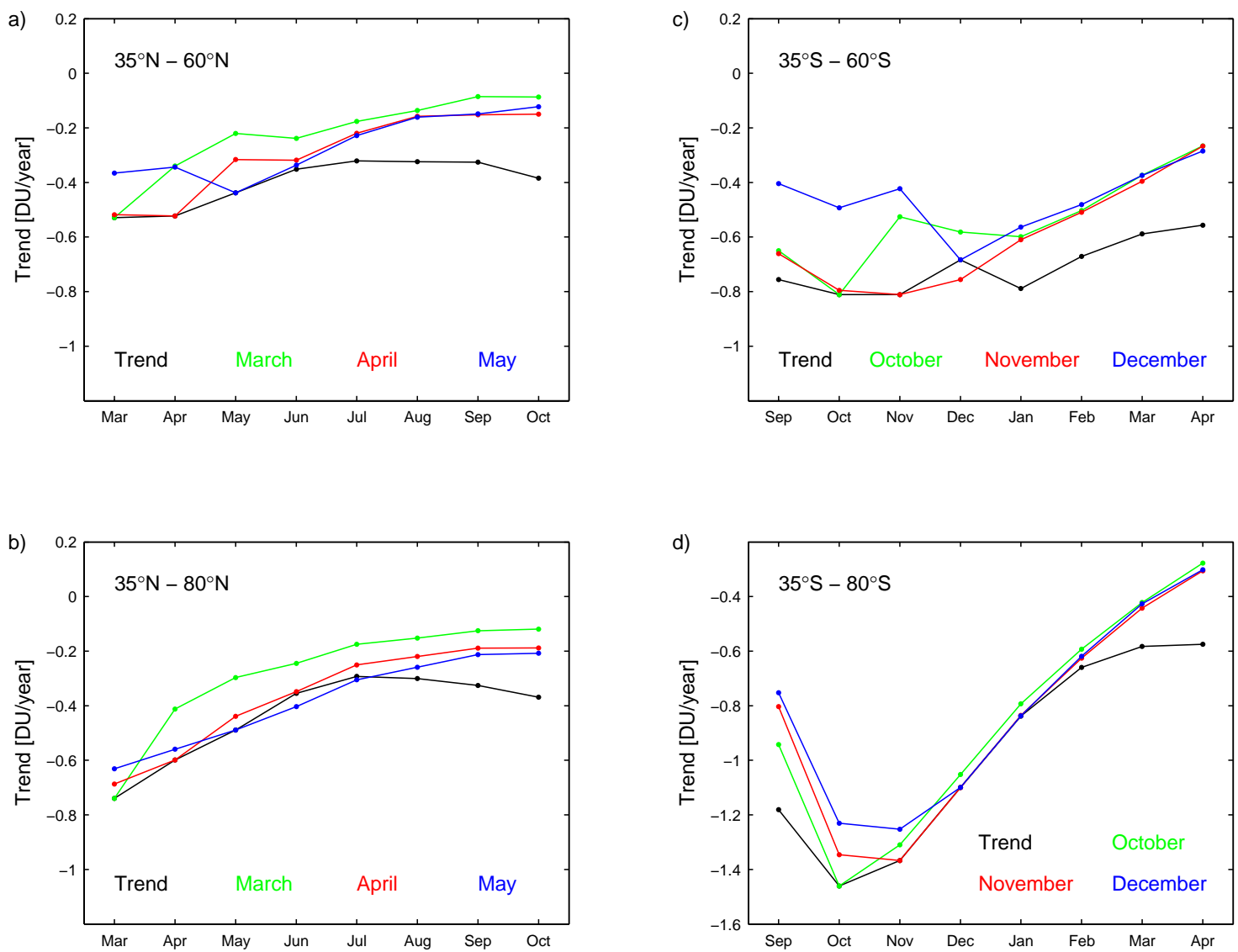

Fig. 9. Total ozone trends for the 45-year transient CMAM run (black) and as estimated from the springtime trends (from March, April, or May in the northern hemisphere, and from October, November, or December in the southern hemisphere) together with the regression coefficients estimated from the detrended data. The trends are shown for midlatitudes $\left(35^{\circ}-60^{\circ}\right.$, top), and the entire extratropical region $\left(35^{\circ}-80^{\circ}\right.$, bottom) for the northern (left) and southern (right) hemispheres. The trends are based on a fit to EESC and are expressed in terms of DU/year during the 1980s (see text for details).

is not true for the midlatitudes alone if polar ozone variations are sufficiently large compared to midlatitude variations. This is true in the southern hemisphere for both observations and CMAM, where the ozone hole contributes to midlatitude summertime trends, elevating them above what would be expected based on midlatitude springtime trends and leading to a relatively weak seasonality of the midlatitude trends. For CMAM this is also true in the northern hemisphere - and in contrast to the observations - because of the relatively large impact, compared to observations, of the CMAM polar anomalies. This results from an unrealistically small midlatitude ozone variability rather than an unrealistically large polar variability.

Acknowledgements. This work was initiated during an earlier visit by S. Tegtmeier to the University of Toronto and has been supported by funding from the Natural Sciences and Engineering Research Council of Canada, the Canadian Foundation for Climate and Atmospheric Sciences, the Canadian Space Agency, and Environment Canada. The authors are indebted to S. Beagley,
A. Jonsson, and J. de Grandpré for assistance with the CMAM data, to V. Fioletov for helpful discussion, and to R. Stolarski and S. Frith from NASA for making the merged satellite data set available. Work at AWI was supported by the EC under contract 505390-GOCE-CT-2004 (SCOUT-O3).

Edited by: M. Dameris

\section{References}

Austin, J., Shindell, D., Beagley, S. R., Brühl, C., Dameris, M., Manzini, E., Nagashima, T., Newman, P., Pawson, S., Pitari, G., Rozanov, E., Schnadt, C. and Shepherd, T. G.: Uncertainties and assessments of chemistry-climate models of the stratosphere, Atmos. Chem. Phys., 3, 1-27, 2003, http://www.atmos-chem-phys.net/3/1/2003/.

Beagley, S. R., de Grandpré, J., Koshyk, J. N., McFarlane, N. A., and Shepherd, T. G.: Radiative-dynamical climatology of the 
first-generation Canadian Middle Atmosphere Model, Atmos.Ocean, 35, 293-331, 1997.

de Grandpré, J., Beagley, S. R., Fomichev, V. I., Griffioen, E., McConnell, J. C., Medvedev, A. S., and Shepherd, T. G.: Ozone climatology using interactive chemistry: Results from the Canadian Middle Atmosphere Model, J. Geophys. Res., 105, $26475-$ 26 491, 2000.

Eyring, V., Butchart, N., Waugh, D. W., Akiyoshi, H., Austin, J., Bekki, S., Bodeker, G. E., Boville, B. A., Brhl, C., Chipperfield, M. P., Cordero, E., Dameris, M., Deushi, M., Fioletov, V. E., Frith, S. M., Garcia, R. R. Gettelman, A., Giorgetta, M. A., Grewe, V., Jourdain, L., Kinnison, D. E., Mancini, E., Manzini, E., Marchand, M., Marsh, D. R., Nagashima, T., Newman, P. A., Nielsen, J. E., Pawson, S., Pitari, G., Plummer, D. A., Rozanov, E., Schraner, M., Shepherd, T. G., Shibata, K., Stolarski, R. S., Struthers, H., Tian, W., and Yoshiki, M.: Assessment of temperature, trace species and ozone in chemistry-climate model simulations of the recent past, J. Geophys. Res., 111, D22308, doi:10.1029/2006JD007327, 2006.

Fioletov, V. E., Bodeker, G. E., Miller, A. J., McPeters, R. D. and Stolarski, R.: Global and zonal total ozone variations estimated from ground-based and satellite measurements: 1964-2000, J. Geophys. Res., 107, 4647, doi:10.1029/2001JD001350, 2002.
Fioletov, V. E. and Shepherd, T. G.: Seasonal persistence of midlatitude total ozone anomalies, Geophys. Res. Lett., 30, 1417, doi:10.1029/2002GL016739, 2003.

Fioletov, V. E. and Shepherd, T. G.: Summertime total ozone variations over middle and polar latitudes, Geophys. Res. Lett., 32, L04807, doi: 10.1029/2004GL022080, 2005.

Frith, S., Stolarski, R., and Bhartia, P. K.: Implications of version 8 TOMS and SBUV data for long-term trend analysis, Proceedings of the Quadrennial Ozone Symposium-2004, edited by: Zerefos, C., 65-66, 2004.

Weber, M., Dhomse, S., Wittrock, F., Richter, A., Sinnhuber, B. M. and Burrows, J. P.: Dynamical control of $\mathrm{NH}$ and $\mathrm{SH}$ winter/spring total ozone from GOME observations in 1995-2002, Geophys. Res. Lett., 30, 1583, doi:10.1029/2002GL016799, 2003.

WMO: Scientific Assessment of Ozone Depletion: 1998, World Meteorological Organisation Global Ozone Research and Monitoring Project Report No. 44, Geneva, 1999.

WMO: Scientific Assessment of Ozone Depletion: 2002, World Meteorological Organisation Global Ozone Research and Monitoring Project Report No. 47, Geneva, 2003. 